\title{
Biocompatibility and bioactivity of calcium silicate- based endodontic sealers in human dental pulp cells
}

\author{
Leticia Boldrin MESTIERI', Ana Lívia GOMES-CORNÉLIO'1, Elisandra Márcia RODRIGUES', Loise Pedrosa SALLES², \\ Roberta BOSSO-MARTELO', Juliane Maria GUERREIRO-TANOMARU1', Mário TANOMARU-FILHO'
}

\footnotetext{
1- Universidade Estadual Paulista, Escola de Odontologia, Departamento de Odontologia Restauradora, Araraquara, SP, Brazil.

2- Universidade de Brasília, Instituto de Biologia, Departamento de Biologia Celular, Brasília, DF, Brazil.
}

Corresponding address: Mário Tanomaru-Filho - Rua Humaitá, 1680 - Caixa Postal 331 - Centro - 14801-903 - Araraquara - SP - Brazil - Phone: +55-163301-6390 - Fax: +55-16-3301-6392 - e-mail: tanomaru@uol.com.br

Submitted: April 16, 2015 - Modification: July 20, 2015 - Accepted: July 29, 2015

\section{ABSTRACT}

M ineral Trioxide Aggregate (MTA) is a calcium silicate-based material. New sealers have been developed based on calcium silicate as MTA Fillapex and MTA Plus. Objective: The aim of this study was to evaluate biocompatibility and bioactivity of these two calcium silicate-based sealers in culture of human dental pulp cells (hDPCs). Material and Methods: The cells were isolated from third molars extracted from a 16-year-old patient. Pulp tissue was sectioned into fragments with approximately $1 \mathrm{~mm}^{3}$ and kept in supplemented medium to obtain hDPCs adherent cultures. Cell characterization assays were performed to prove the osteogenic potential. The evaluated materials were: MTA Plus (MTAP); MTA Fillapex (MTAF) and FillCanal (FC). Biocompatibility was evaluated with MTT and Neutral Red (NR) assays, after hDPCs exposure for $24 \mathrm{~h}$ to different dilutions of each sealer extract $(1: 2$, $1: 3$ and 1:4). Unexposed cells were the positive control (CT). Bioactivity was assessed by alkaline phosphatase (ALP) enzymatic assay in cells exposed for one and three days to sealer extracts ( $1: 4$ dilution). All data were analyzed by ANOVA and Tukey post-test ( $p \leq 0.05 \%)$. Results: MTT and NR results showed suitable cell viability rates for MTAP at all dilutions (90-135\%). Cells exposed to MTAF and FC (1:2 and 1:4 dilutions) showed significant low viability rate when compared to $C T$ in MTT. The NR results demonstrated cell viability for all materials tested. In MTAP group, the cells ALP activity was similar to CT in one and three days of exposure to the material. MTAF and FC groups demonstrated a decrease in ALP activity when compared to CT at both periods of cell exposure. Conclusions: The hDPCs were suitable for the evaluation of new endodontic materials in vitro. MTAP may be considered a promising material for endodontic treatments.

Keywords: Dental pulp. Silicate cement. Cell viability. Alkaline phosphatase.

\section{NTRODUCTI ON}

MTA is indicated as the material of choice for root-end-fillings and root perforation treatment ${ }^{24}$. The bioactivity of MTA led to the interest at the development of new dental materials based on calcium silicates, including root canal sealers ${ }^{26}$.

MTA Fillapex and MTA Plus are two endodontic calcium silicate-based sealers. MTA Fillapex (Angelus Industry Dental Products S/A, Londrina, PR, Brazil) composition consists of MTA associated with resins and pigments. MTA Plus (Avalon Biomed Inc.,
Sarasota, FL, USA) is composed of calcium silicates in smaller particles than MTA, according to the manufacturer. Moreover, MTA Plus presents a watersoluble salt-free gel as a vehicle. This gel might improve the consistency, solubility and adhesiveness to dentin walls ${ }^{18}$, allowing its use as a sealer. Studies evaluating MTA Fillapex biocompatibility and bioactivity in osteoblastic cells showed cytotoxicity effect of this sealer in the first periods of cells exposure ${ }^{20,27}$. However, for extended periods, cell viability and ALP enzyme activity have substantially increased. The production of mineralized nodules 
by Alizarin Red staining was observed as well, demonstrating the cement biocompatibility and bioactivity after the setting time ${ }^{20}$.

In other study, MTA Fillapex presented lower adhesion to dentin walls when compared to MTA Plus $^{16}$. Furthermore, the authors suggest that MTA Plus has a higher biomineralization potential than MTA Fillapex, being able to form apatite deposits in collagen fibrils inside the dentinal tubules, being similar to a tag between dentin-MTA Plus interface. When evaluating MTA Plus bioactive potential, a recent study showed that this cement is similar to ProRoot MTA (Dentsply Tulsa Dental Specialties, York, PA, USA), and releases calcium ions when in contact with water or HBSS (Hank's saline based solution $)^{6}$.

Although these sealers were launched in the market the last couple of years, literature still lacks information about their biological properties. The aim of this study was to evaluate the biocompatibility and bioactivity of MTA Plus and MTA Fillapex in primary culture of human dental pulp cells (hDPCs). The hDPCs are a suitable model to evaluate cytotoxicity of different dental materials ${ }^{11}$. This cell line is also used to estimate the effects of MTA and several calcium silicate-based cements in cell culture, demonstrating its cytocompatibility and bioactivity in vitro ${ }^{17,26}$.

\section{MATERI AL AND METHODS}

\section{Dental pulp cells explants and cell culture conditions}

After approval from the Institutional Research Ethics Committee, patients with third molars at the stage of incomplete root formation, indicated to extraction for orthodontic reasons, were selected for this study. Dental pulps were collected via apical opening using a Hedströen file (Maillefer, Dentsply, Chemin du Verger, Ballaigues, Switzerland) and stored in a culture dish $(35 \times 10 \mathrm{~mm})$ containing Alpha Modification Minimum Essential Eagle's Medium (a-MEM, Sigma-Aldrich, St. Louis, MO, USA) supplemented with $10 \%$ fetal bovine serum (FBS, Gibco, Life Technologies, Grand Island, NY, USA) and $1 \%$ penicillin and streptomycin (PenStrep, Gibco). The pulp tissues were sectioned into fragments of approximately $1 \mathrm{~mm}^{3}$ and kept in supplemented a-MEM at $37^{\circ} \mathrm{C}, 95 \%$ humidity and $5 \% \mathrm{CO}_{2}$. The culture medium was changed $24 \mathrm{~h}$ after the pulp collection and every $48 \mathrm{~h}$ to obtain explants of human dental pulp cells (hDPCs). Successive passages were prepared for cellular expansion. The experiments were performed with cells from the fourth passage, and were repeated three times independently $(n=3 /$ group).

\section{Preparation of endodontic sealer extracts}

The experimental groups and the preparation proportions are described in Figure 1. Endodontic sealers were prepared according to manufactures instructions. FillCanal (FC) was prepared according to Grossman technique ${ }^{9}$, and MTA Plus (MTAP) was prepared with the vehicle for root canal filling consistency. Thereafter, $1 \mathrm{~mL}$ of each sealer was individually placed in wells of a 12-well plate (TPP, Techno Plastic Products, Zollstrasse, Trasadingen, Suíça) and spread to fill the bottom completely. The plates with the samples were kept in an incubator at $37^{\circ} \mathrm{C}, 95 \%$ humidity and $5 \% \mathrm{CO}_{2}$ during $24 \mathrm{~h}$ for the initial setting time of the materials. After this period, the specimens were exposed to ultraviolet light (UV) in a laminar flow for 30 min each side to disinfection ${ }^{13}$. The wells were filled with $5 \mathrm{~mL}$ of a-MEM supplemented with $1 \%$ PenStrep and incubated at $37^{\circ} \mathrm{C}, 95 \%$ humidity and $5 \% \mathrm{CO}_{2}$ for additional $24 \mathrm{~h}$, in order to obtain the sealer extracts.

\section{Cytotoxicity assays}

Cytotoxicity was assessed by MTT (3-(4,5-dimethyl-thiazoyl)-2,5-diphenyl-tetrazolium bromide) and Neutral Red (NR) assays. hDPCs were plated at the concentration of $2 \times 10^{5}$ cells per well in 96 -well plates (TPP) containing supplemented a-MEM culture medium and cultured for $24 \mathrm{~h}$ at $37^{\circ} \mathrm{C}, 95 \%$ humidity and $5 \% \mathrm{CO}_{2}$ to obtain adherent cells prior to the material exposure. hDPCs were exposed to the sealers extracts in dilutions using culture medium without FBS of $1: 2,1: 3$ and $1: 4$ for one day, according to ISO $10993-5^{12}$.

MTT is based on the conversion of tetrazolium salt to insoluble violet formazan crystals, determining the cytotoxicity by measuring cell viability rate. For this experiment, sealers extracts were replaced by $100 \mu \mathrm{L}$

\begin{tabular}{|c|c|c|c|}
\hline Group & Material & Reference & Proportion \\
\hline MTAP & MTA Plus & $\begin{array}{c}\text { Avalon Biomed Inc., } \\
\text { Bradenton, FL, USA }\end{array}$ & $1 \mathrm{~g}: 350 \mu \mathrm{L}$ \\
\hline MTAF & MTA Fillapex & $\begin{array}{c}\text { Angelus S/A, Londrina, PR, } \\
\text { Brasil }\end{array}$ & $1: 1$ \\
\hline FC & FillCanal & $\begin{array}{c}\text { Technew, Rio de Janeiro, } \\
\text { RJ, Brasil }\end{array}$ & $1 \mathrm{~g}: 200 \mu \mathrm{L}$ \\
\hline
\end{tabular}

Figure 1- Endodontic sealers evaluated 
of a $5 \mathrm{mg} / \mathrm{mL}$ MTT solution (Sigma-Aldrich), followed by incubation at $37^{\circ} \mathrm{C}, 95 \%$ humidity and $5 \% \mathrm{CO}_{2}$ for $3 \mathrm{~h}$. Thereafter, the content of the well was removed and the colorimetric product solubilized in $100 \mu \mathrm{L}$ of acidified isopropanol $0.04 \mathrm{~N}$ (Sigma-Aldrich). The optical densities of the solutions were measured in a spectrophotometer (Elx800; Instrumentos BioTek, Winooski, VT, USA) at $570 \mathrm{~nm}$ wavelength ${ }^{27}$. The absorbance readouts were normalized with the absorbance of the group of cells exposed to a-MEM (CT), and represented the activity of the viable cells.

NR is a vital dye that is incorporated through endocytosis and accumulated on the lysosome of cells that have their membranes intact. For this experiment, sealers extracts were replaced by $0.1 \mathrm{~mL}$ a-MEM medium containing $50 \mu \mathrm{g} \mathrm{NR} / \mathrm{mL}$ (Sigma-Aldrich) followed by incubation at $37^{\circ} \mathrm{C}, 95 \%$ humidity and $5 \% \mathrm{CO}_{2}$ for $3 \mathrm{~h}$. Then, the content of the well was removed and the colorimetric product solubilized in $100 \mu \mathrm{L}$ of an ethanol solution (50\% ethanol and $1 \%$ acetic acid) (Sigma-Aldrich). The optical densities of the solutions were measured in a spectrophotometer (Elx800) at $570 \mathrm{~nm}^{21}$.

\section{ALP enzyme activity}

ALP is an enzyme present in the plasma membrane that is associated with the mineralization process, and it is one of the major markers of osteoblast activity in the cells ${ }^{3}$. The bioactivity assay by ALP enzyme activity was performed with hDPCs at the concentration of $2 \times 10^{4}$ cells per well in 12 -well plates (TPP), as previously described. The assay was performed in time intervals of one and three days. All assays were performed in triplicate and repeated three independent times ( $n=3 /$ group). Cells exposed to culture medium were the control of group (CT).

ALP activity was evaluated in accordance to the release of tymolphtaleine from tymolphtaleine monophosphate using Alkaline Phosphatase kit (Labtest Diagnóstica, Lagoa Santa, MG, Brazil).
hDPCs were lysed for 30 min at ambient temperature using Sodium Lauryl Sulfate solution 1:1 (SDS, Sigma-Aldrich), and the assay was performed according to the manufacturer instructions. Absorbance was measured at the wavelength of 590 $\mathrm{nm}$ in a spectrophotometer. The data were expressed as ALP activity ( $\mu \mathrm{mol}$ tymophtaleine/min/L) ${ }^{19}$.

\section{Statistical analysis}

The data were analyzed by Kolmogorov-Smirnov test, obtaining a normal distribution. Therefore, we performed ANOVA and Tukey tests post hoc, considering a level of significance of 5\% (GraphPad Prism 5 software, GraphPad Software Inc., San Diego, CA, USA). All data is presented as mean and standard deviation of the mean.

\section{RESULTS}

The MTT assay (Figure 2) showed 80-120\% of viability to hDPCs exposed to MTAP at all concentrations evaluated, being similar to the negative control of cytotoxicity $(p>0.05)$. The MTAP group viability rate was similar in the dilution of $1: 4$ to the other groups ( $p>0.05)$, although MTAF and FC groups viability rate showed significant difference in comparison to the CT. MTAF showed lower viability rate than $\mathrm{CT}$ at all concentrations evaluated. At NR assay (Figure 3), hDPCs exposed to MTAP showed significant higher viability rate $(130-135 \%)$ than CT for all dilutions evaluated $(p<0.05)$. MTAF showed the lowest viability of all groups in $1: 2$ dilution $(p<0.05)$, however it increased in the dilutions of $1: 3$ and $1: 4(p<0.05)$. FC demonstrated good viability in all dilutions, being similar to MTAF in 1:4 ( $p>0.05)$.

In ALP bioactivity assay (Figure 4 ), MTAP showed similar activity to the control group at both periods of time evaluated ( $p>0.05$ ), while the other groups demonstrated significant lower ALP activity when compared to CT $(p<0.05)$. There was a tendency of

\section{MTT Assay}

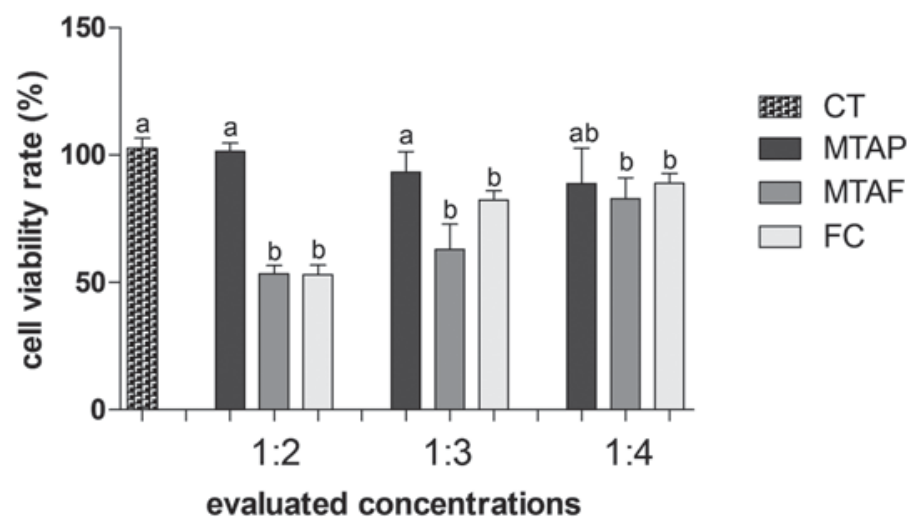

Figure 2- Cell viability rate (\%) according to MTT assay in human dental pulp cells (hDPCs) exposed to MTA Plus (MTAP), MTA Fillapex (MTAF), FillCanal (FC) and culture medium used as control (CT). Bars with different letters represent significant differences between groups in each concentration of the material extracts $(p<0.05)$ 


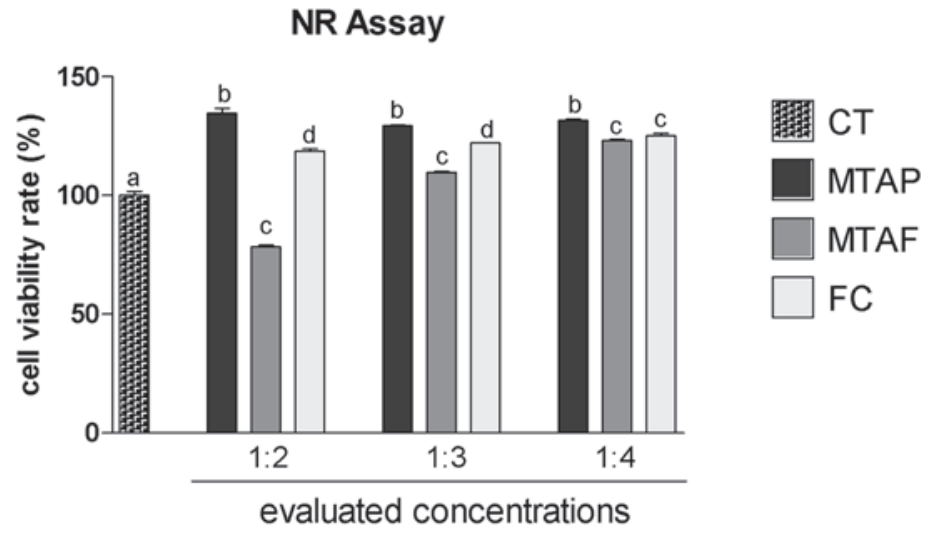

Figure 3- Cell viability rate (\%) according to NR assay in human dental pulp cells (hDPCs) exposed to MTA Plus (MTAP), MTA Fillapex (MTAF), FillCanal (FC) and culture medium used as control (CT). Bars with different letters represent significant differences between groups in each concentration of the material extracts $(p<0.05)$

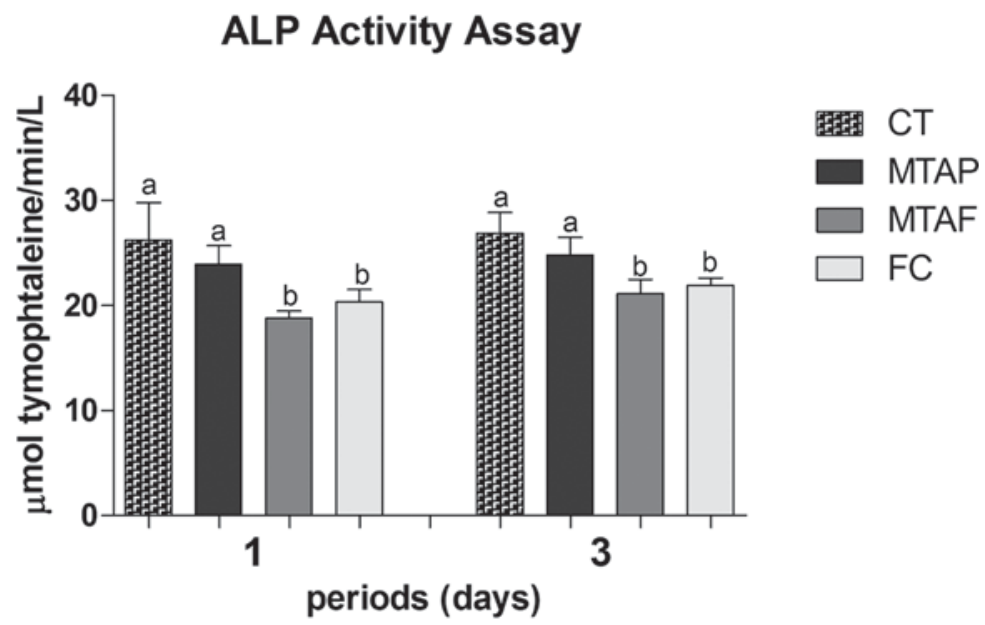

Figure 4- Alkaline phosphatase (ALP) enzyme activity in human dental pulp cells (hDPCs) exposed to MTA Plus (MTAP), MTA Fillapex (MTAF), FillCanal (FC) and culture medium used as control (CT). Bars with different letters represent significant differences between groups in each period of time $(p<0.05)$

ALP activity increase in a time-dependent manner at all groups.

\section{DISCUSSION}

hDPCs may represent a different population of differentiated and undifferentiated cells with great potential for pulp tissue and dentin regeneration. They can be successfully applied in studies to evaluate new biomaterials ${ }^{2}$, including endodontic sealers. Studies in the literature reported that MTA is capable to stimulate odontogenic differentiation in dental pulp mesenchymal cells 7,22 . In this study, human dental pulp was collected from third molars referred to extractions for orthodontic reasons, and obtained explants of hDPCs to investigate possible cytotoxic effects and the bioactivity of MTAP, MTAF and FC.

Furthermore, MTT and NR assays demonstrated higher viability rate to MTAP at all concentrations evaluated, and there was no evidence of cytotoxic effect. All materials presented similar viability in the higher dilution (1:4) on MTT assay. Concentrationdependent results were also described by other authors when evaluating the viability of MTA ProRoot and MTAP in rat odontoblastic cells (MDPC23), concluding that the cytotoxic risks become negligible after the dilution of the components ${ }^{8}$. MTAF obtained similar results to FC. The viability of MTAF has been evaluated in several cell types, such as fibroblasts ${ }^{4,23}$, osteoblasts ${ }^{21}$ and human dental cell cultures ${ }^{10}$, demonstrating cytotoxic results in less than 7-day periods ${ }^{27}$. In this study, the cytotoxicity of MTAF may be considered moderate to low (50-80\%, approximately) and concentration-dependent, after $24 \mathrm{~h}$ setting-time. Zinc oxide and eugenol cements as FC are considered cytotoxic both in vitro and in vivo, causing tissue inflammation and even bone resorption ${ }^{1}$. In addition, the literature demonstrated that these cements are capable of inducing the expression of cyclooxygenase-2 and nuclear factor kappa $B$, an immune mediator involved in cellular 
responses to stress, cytokines, free radicals, UV radiation, oxidation of LDL and bacterial and viral antigens ${ }^{14}$. MTAF cytotoxicity can be associated with its toxic components, such as salicylate resin, which can induce apoptosis 5 .

The bioactivity was analyzed in accordance to ALP enzymatic assay. The progressive increase in ALP activity is marked in bone cells ${ }^{15}$. Besides the bioactivity, ALP expression indicates the potential of the cells for differentiation ${ }^{25}$. Therefore, the evaluation of this enzyme allows the determination of the material bioactivity and its potential to promote repair with formation of mineralized tissue. The results showed an increase in ALP enzyme activity over time for cells exposed to all materials. MTAP presented results similar to the control group in both evaluated periods, and higher than the other cements groups. Other studies showed that after the initial period of cytotoxicity, MTAF sealer is able to promote bioactivity, stimulating the deposition of mineralized nodules and increasing ALP activity ${ }^{20}$, corroborating the results of the present study.

\section{CONCLUSION}

This study shows that MTAP presents biocompatibility and bioactivity in the primary culture of cells from human dental pulp. MTAP can be considered a suitable material for root canal filling. MTAF shows initial cytotoxicity.

\section{ACKNOWLEDGEMENTS}

We would like to thank FAPESP - São Paulo Research Foundation (Processes 2011-18239-4 and 2012/13268-9).

We also thank CNPq - National Council for Scientific and Technological Development (Process 475068/2010-6, MCT/CNPq 14/2010).

\section{REFERENCES}

1- Al-Hiyasat AS, Tayyar M, Darmani H. Cytotoxicity evaluation of various resin based root canal sealers. Int Endod J. 2010;43:148-53. 2- Atari M, Barajas M, Hernández-Alfaro F, Gil C, Fabregat M, Ferrés Padró $E$, et al. Isolation of pluripotent stem cells from human third molar dental pulp. Histol Histopathol. 2011;26:1057-70.

3- Beck GR Jr. Inorganic phosphate as a signaling molecule in osteoblast differentiation. J Cell Biochem. 2003;90:234-43.

4- Bin CV, Valera MC, Camargo SE, Rabelo SB, Silva GO, Balducci I, et al. Cytotoxicity and genotoxicity of root canal sealers based on mineral trioxide aggregate. J Endod. 2012;38:495-500.

5- Braga JM, Oliveira RR, Castro Martins R, Vieira LQ, Sobrinho AP. Assessment of the cytotoxicity of a mineral trioxide aggregate-based sealer with respect to macrophage activity. Dent Traumatol. 2015. Epub ahead of print.

6- Camilleri J, Formosa L, Damidot D. The setting characteristics of MTA Plus in different environmental conditions. Int Endod J. 2013;46:831-40.

7- Chang SW, Lee SY, Kum KY, Kim EC. Effects of ProRoot MTA, Bioaggregate, and Micromega MTA on odontoblastic differentiation in human dental pulp cells. J Endod. 2014;40:113-8.
8- Eid AA, Gosier JL, Primus CM, Hammond BD, Susin LF, Pashley $\mathrm{DH}$, et al. In vitro biocompatibility and oxidative stress profiles of different hydraulic calcium silicate cements. J Endod. 2014;40:25560.

9- Grossman LI. Physical properties of root canal cements. J Endod. 1976;2:166-75.

10- Güven EP, Yalvaç ME, Kayahan MB, Sunay $H$, Şahın F, Bayirli G. Human tooth germ stem cell response to calcium-silicate based endodontic cements. J Appl Oral Sci. 2013;21:351-7.

11- Guven EP, Yalvac ME, Sahin F, Yazici MM, Rizvanov AA, Bayirli G. Effect of dental materials calcium hydroxide-containing cement, mineral trioxide aggregate, and enamel matrix derivative on proliferation and differentiation of human tooth germ stem cells. J Endod. 2011;37:650-6.

12- International Organization for Standardization. ISO 10993-5: Biological evaluation of medical devices - Part 5: Tests for in vitro cytotoxicity. Geneva: ISO; 2009.

13- Katara G, Hemvani N, Chitnis S, Chitnis V, Chitnis DS. Surface disinfection by exposure to germicidal UV light. Indian J Med Microbiol. 2008;26:241-2.

14- Lee YY, Yang SF, Ho WH, Lee YH, Hung SL. Eugenol modulates cyclooxygenase-2 expression through the activation of nuclear factor kappa B in human osteoblasts. J Endod. 2007;33:1177-82. 15- Millán JL. Mammalian alkaline phosphatases: from biology to applications in medicine and biotechnology. $1^{\text {st }}$ ed. Weinheim: Wiley-VCH Verlag; 2006.

16- Neelakantan P, Grotra D, Sharma S. Retreatability of 2 mineral trioxide aggregate-based root canal sealers: a cone-beam computed tomography analysis. J Endod. 2013;39:893-6.

17- Paranjpe A, Smoot T, Zhang H, Johnson JD. Direct contact with mineral trioxide aggregate activates and differentiates human dental pulp cells. J Endod. 2011;37:1691-5.

18- Qi YP, Li N, Niu LN, Primus CM, Ling JQ, Pashley DH, et al. Remineralization of artificial dentinal caries lesions by biomimetically modified mineral trioxide aggregate. Acta Biomater. 2012;8:836-42. 19- Rosa AL, Beloti MM. Development of the osteoblast phenotype of serial cell subcultures from human bone marrow. Braz Dent J. 2005; 16:225-30.

20- Salles LP, Gomes-Cornélio AL, Guimarães FC, Herrera BS, Bao SN, Rossa-Junior C, et al. Mineral trioxide aggregate-based endodontic sealer stimulates hydroxyapatite nucleation in human osteoblast-like cell culture. J Endod. 2012;38:971-6.

21- Scelza MZ, Linhares AB, Silva LE, Granjeiro JM, Alves GG. A multiparametric assay to compare the cytotoxicity of endodontic sealers with primary human osteoblasts. Int Endod J. 2012;45:12-8. 22- Seo MS, Hwang KG, Lee J, Kim H, Baek SH. The effect of mineral trioxide aggregate on odontogenic differentiation in dental pulp stem cells. J Endod. 2013;39:242-8.

23- Silva EJ, Santos CC, Zaia AA. Long-term cytotoxic effects of contemporary root canal sealers. J Appl Oral Sci. 2013;21:43-7.

24- Torabinejad M, Parirokh M. Mineral trioxide aggregate: a comprehensive literature review - part II: leakage and biocompatibility investigations. J Endod. 2010;36:190-202.

25- Wang Y, Yan M, Wang Z, Wu J, Wang Z, Zheng Y, et al. Dental pulp stem cells from traumatically exposed pulps exhibited an enhanced osteogenic potential and weakened odontogenic capacity. Arch Oral Biol. 2013;58:1709-17.

26- Woo SM, Hwang YC, Lim HS, Choi NK, Kim SH, Kim WJ, et al. Effect of nifedipine on the differentiation of human dental pulp cells cultured with mineral trioxide aggregate. J Endod. 2013;39:801-5. 27- Yoshino P, Nishiyama CK, Modena KC, Santos CF, Sipert CR. In vitro cytotoxicity of white MTA, MTA Fillapex ${ }^{\circledR}$ and Portland cement on human periodontal ligament fibroblasts. Braz Dent J. 2013;24:111-6. 